\title{
Study on Application of Grey Relational Decision-Making on Determination of Ship Collision Risk Degree
}

\author{
Hongdan Liu * \\ College of Automation \\ Harbin Engineering University \\ Harbin, China \\ liuhongdan131@126.com \\ * Corresponding Author \\ Sheng Liu \\ College of Automation \\ Harbin Engineering University \\ Harbin,China \\ liusheng@hrbeu.edu.cn
}

\author{
Siliang Xu \\ College of Automation \\ Harbin Engineering University \\ Harbin, China \\ xusiliang@hrbeu.edu.cn
}

\author{
Lanyong Zhang \\ College of Automation \\ Harbin Engineering University \\ Harbin, China \\ zhanglanyong@hrbeu.edu.cn
}

\begin{abstract}
In the realization process of multi-ship collision avoidance path planning, it is the foundation for decisionmaking of collision avoidance opportunity and behavior to accurately and rapidly determine the key collision avoidance target ship and the sequence for the ship to avoid collision with various target ships. Therefore, this paper introduces grey relational decision-making to comprehensively analyze, evaluates and selects key collision avoidance ship on the basis of risk degree evaluation parameters including distance to closest point of approaching (DCPA), time to closest point of approaching (TCPA), ship speed rate (K), and safe distance of approach (SDA) in multi-ship collision avoidance decision-making. Finally, the influence of various risk degree evaluation parameters on collision risk degree is analyzed through simulation, and an interactive interface of target ship collision risk degree ranking is established, to verify feasibility and superiority of this method.
\end{abstract}

Keywords-multi-ship encounter; ship collision avoidance; key collision avoidance ship; grey relational decision-making; simulation interface

\section{INTRODUCTION}

In terms of theories and methods of determining ship collision risk degree, many new ideas and methods are proposed under the joint effort of numerous experts and scholars. At the beginning, researches on collision risk degree at home and abroad are based on traffic flow theory, and the collision risk degree in a specific water area is evaluated according to ship encounter rate that is number of encounters and historical collision accidents in the water area ${ }^{[1-3]}$. According to stipulations in Article 7 of Rule and experience of seaman on the sea, determination of collision risk is related to many factors, however, the fundamental factors are DCPA and TCPA, which still exists the gap from practical sailing situations. Therefore, decisionmaking factors of key collision avoidance ship are analyzed in this paper, and meanwhile comprehensive evaluation is conducted by combining with grey relational decision-making, and key collision avoidance ship is determined via grey relational degree.

Besides, judgment time of seaman is shortened and seaman's efficiency of executing multi-ship collision avoidance is enhanced by establishing an interactive collision risk degree analysis interface.

\section{INFLUENCE FACTORS OF SHIP COLLISION RISK DEGREE}

\section{A. DCPA and TCPA}

In order to conduct real-time calculation for DCPA and TCPA between own ship and the target ship, a rectangular plane coordinate system can be set up, as shown in Fig. 1. In this coordinate system, own ship is set as the center which will move with our own ship. The coordinate origin $\mathrm{O}$ is located in centroid of our ship; $\mathrm{y}$ axis is in the platform surface of our ship, parallel to the platform axis (keel line) and pointing at the front; $\mathrm{x}$ axis is in the platform surface and determined by right-hand system rule. In this way, when the target ship moves into the radar sight range of our ship, radar will immediately convert position coordinates of the target ship at any time into the coordinate system of our ship at the current time point through real-time detection for the target ship and proper coordinate transformation or rotation transformation. 


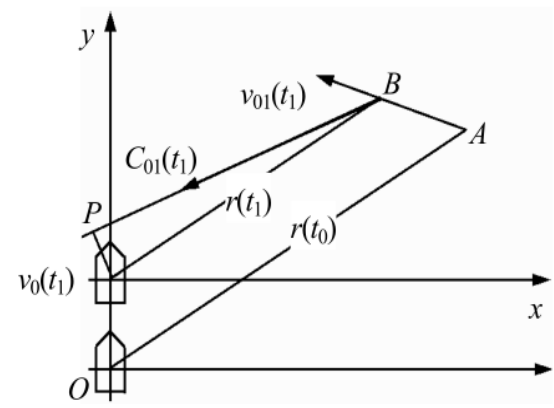

Figure 1. Schematic diagram for motion state of the ship

Suppose that speed of own ship is $v_{0}$ and the heading direction is $C_{0}$; speed of the target ship is $v_{t}$ and the heading direction is $C_{t}$; azimuth angle of the target ship against own ship is $B$; the distance between the target ship and our ship is $D$.

(1) Calculation for relative speed $v_{r}$

$$
v_{r}=\sqrt{v_{t}^{2}+v_{0}^{2}-2 v_{t} v_{0} \cos \alpha}
$$

(1)

Where $\alpha=C_{0}-C_{t} \quad\left(\alpha= \pm 0^{\circ} \sim 180^{\circ}\right.$ ).

(2) Calculation for relative heading direction

$$
\begin{cases}C_{r}=C_{0}+Q & \left(\alpha>0^{\circ}\right) \\ C_{r}=C_{0}-Q & \left(\alpha<0^{\circ}\right)\end{cases}
$$

Where

$$
Q=\arccos \left(\frac{v_{r}^{2}+v_{0}^{2}-v_{t}^{2}}{2 v_{r} v_{0}}\right)
$$

(4) Calculation for DCPA and TCPA

$$
\left\{\begin{array}{l}
D C P A=D \sin \left(Q_{r}\right) \\
T C P A=D \cos \left(Q_{r}\right) / v_{r}
\end{array}\right.
$$

(4)

\section{B. Safe Distance of Approach (SDA)}

According to Item 4 in Article 8 of Rule, actions taken to avoid collision with other ships should guarantee that the two ships travel at a safe distance. SDA is related to many factors during sea voyage, such as visibility and weather. SDA based on ship domain is adopted according to literature [4-5]. Security domain value of the ship will be corrected according to different directions of the coming ship:

$$
S D A=\left\{\begin{array}{lc}
1.1-\frac{B}{180^{\circ}} \times 0.2 & 0^{\circ} \leq B \leq 112.5^{\circ} \\
1.0-\frac{B}{180^{\circ}} \times 0.4 & 112.5^{\circ}<\mathrm{B} \leq 180^{\circ} \\
1.0-\frac{360^{\circ}-B}{180^{\circ}} \times 0.4 & 180^{\circ}<\mathrm{B} \leq 247.5^{\circ} \\
1.1-\frac{360^{\circ}-B}{180^{\circ}} \times 0.4 & 247.5^{\circ}<\mathrm{B} \leq 360^{\circ}
\end{array}\right.
$$

Where, $B$ is azimuth angle of the target ship.

\section{GREY RELATIONAL DECISION-MAKING}

Grey relational analysis is an important research content of grey system ${ }^{[6-9]}$. Grey relational degree refers to measurement for the relevance of the change of factors between two systems with time or different objects. Calculation for relational degree aims to investigate the relevance among relevant factors through the relational degree between two sequences. According to the definition of grey relational degree, calculation for relational degree can be obtained. The realization process of grey relational degree in grey relational decision-making is presented in the following figure:

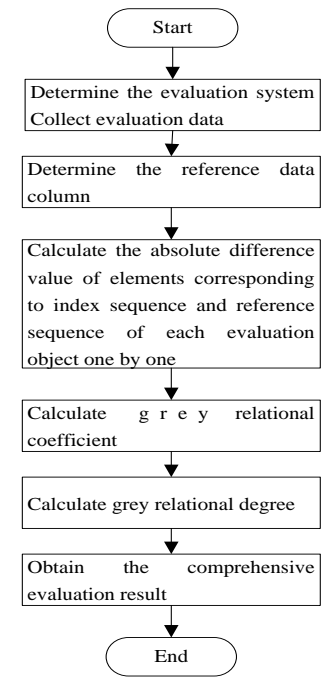

Figure 2. Realization process of grey relational degree

Suppose that $X_{0}=\left(x_{0}(1), x_{0}(2), \cdots, x_{0}(n)\right)$ is system signature sequence, and the formulas are relevant sequences:

$$
\begin{gathered}
X_{1}=\left(x_{1}(1), x_{1}(2), \cdots, x_{1}(n)\right) \\
\vdots \\
X_{i}=\left(x_{i}(1), x_{i}(2), \cdots, x_{i}(n)\right) \\
\vdots \\
X_{m}=\left(x_{m}(1), x_{m}(2), \cdots, x_{m}(n)\right) \\
\gamma\left(X_{0}, X_{i}\right)=\frac{1}{n} \sum_{k=1}^{n} \gamma\left(x_{0}(k), x_{i}(k)\right) \\
\gamma\left(x_{0}(k), x_{i}(k)\right) \text { is given. If the } \\
\text { The real number } \\
\text { four axioms of grey correlation, including normatively, }
\end{gathered}
$$


integrality, couple symmetry and accessibility, are met, then

$$
\gamma\left(X_{0}, X_{i}\right)=\frac{1}{n} \sum_{k=1}^{n} \gamma\left(x_{0}(k), x_{i}(k)\right)
$$

is called grey relational degree of $X_{i}, X_{j} \in X$. In the formula, $r\left(x_{0}(k), x_{i}(k)\right)$ is the correlation coefficient of $X_{i}$ and $X_{j}$ : at point ${ }^{k}$. Moreover, $\xi \in(0,1)$; it is 0.5 in most cases.

$$
r\left(x_{0}(k), x_{i}(k)\right)=\frac{\min _{i} \min _{k}\left|x_{0}(k)-x_{i}(k)\right|+\xi \cdot \max _{i} \max _{k}\left|x_{0}(k)-x_{i}(k)\right|}{\left|x_{0}(k)-x_{i}(k)\right|+\xi \cdot \max _{i} \max _{k}\left|x_{0}(k)-x_{i}(k)\right|}
$$

\section{APPLICATION OF GREY RELATIONAL DECISION- MAKING TO DETERMINATION OF KEY COLLISION AVOIDANCE SHIP}

Suppose that sailing speed of own ship is $v_{0}$ and the heading direction is $C_{0}$. If own ship encounters $m$ ships on the sea, sailing speed of ship $i$ is $v_{i}$ and the heading direction is $C_{i}$. Therefore, azimuth angle of this ship against our ship is $B_{i}$, and the distance from our ship is $D_{i}$. The relative speed of ship $i$ and own ship is $V_{r i}$, relative heading direction is $C_{r i}$, and relative bow bearing is $Q_{r i}$.

Thus $D C P A_{i}, T C P A_{i}$ and ship speed rate $K_{i}$ of own ship and ship $\boldsymbol{i}$ can be obtained. And then, grey relational theory can be used to extract DCPA, TCPA and K of each ship into factor sequence:

$$
X_{i}=\left(x_{i}(1), x_{i}(2), x_{i}(3)\right)
$$

Where,

$x_{i}(1)=D C P A_{i}, x_{i}(2)=T C P A_{i}, x_{i}(3)=K_{i}$; besides, the minimum DCPA, TCPA and $\mathrm{K}$ among all target ships are extracted as signature sequence:

$$
X_{0}=\left(x_{0}(1), x_{0}(2), x_{0}(3)\right)
$$

Where,

$x_{0}(1)=\min \left(D C P A_{i}\right), x_{0}(2)=\min \left(T C P A_{i}\right), x_{0}(3)=\min K_{i}$ Meanwhile, due to the practical situation of multi-ship encounter on the sea, it is impossible for all parameters of two ships to be identical. Therefore, the sequence meets four axioms of grey correlation, and grey correlation can be used to gain the grey relational degree with signature sequence. Grey correlation formula is used to gain the correlation coefficient of each index reference sequence:

$$
r\left(x_{0}(k), x_{i}(k)\right)=\frac{\min _{i} \min _{k}\left|x_{0}(k)-x_{i}(k)\right|+\xi \cdot \max _{i} \max _{k}\left|x_{0}(k)-x_{i}(k)\right|}{\left|x_{0}(k)-x_{i}(k)\right|+\xi \cdot \max _{i} \max _{k}\left|x_{0}(k)-x_{i}(k)\right|} .
$$

Where, $\xi \in(0,1)$; it is 0.5 in most cases. Then, grey relational degree of each ship can be obtained:

$$
r\left(X_{0}, X_{i}\right)=\frac{1}{n} \sum_{k=1}^{n} r\left(x_{0}(k), x_{i}(k)\right)=\frac{1}{n} \sum_{k=1}^{n} r_{0 i}(k)
$$

Ultimately, key collision avoidance ship and collision avoidance sequence of own ship are gained via ranking. The realization process of determining key collision avoidance ship on the basis of grey relational degree is presented in Fig .3.

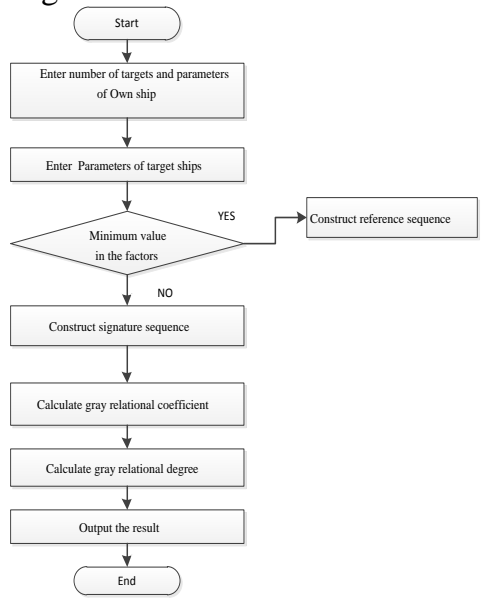

Figure 3. Determining key collision avoidance ship via grey relational degree

\section{SIMULATION RESULT AND ANALYSIS}

\section{A. Realization of Simulation Result}

In order to simulate application of grey relational decision-making in key collision avoidance ship, parameters of own ship are entered: the sailing speed $v_{0}$ is 16 and the heading direction $C_{0}$ is 0 . Besides, parameters of various target ships are entered, so as to gain the values of risk degree evaluation parameters including $D C P A$, TCPA and $K$. Specific values are shown in the following table 1:

(1) Factor sequences of various target ships are gained: $\quad X_{1}=\{-0.5952,8.6040,1.3333,1.1\} \quad$; $X_{2}=\{-0.4881,12.01,1.143,1.1\}$

$X_{4}=\{-0.6881,23.68,1.143,1.033\}$ $X_{5}=\{0.431,41.2,0.8,0.989\}$;

(2) The minimum values of DCPA, TCPA and $K$ between target ships and our ship are gained, and reference 
sequence

$X_{0}=\{-0.6882,8.604,0.8,0.989\}$

is

established;

(3) Grey relational coefficients of various evaluation factors are worked out:

$$
\begin{gathered}
r[0]=\{0.9859,0.9702,0.8339,1.0000,0.8535\} ; \\
r[1]=\{1.0000,0.6571,0.5905,0.3018,0.1667\} \\
r[2]=\{0.9244,0.9500,0.9702,0.9500,1.000\} ; \\
r[3]=\{0.9832,0.9832,0.9832,0.9932,1\}
\end{gathered}
$$$$
\text { (4) Grey relational degree is }
$$
calculated:

$$
R=\{0.97974,0.89686,0.85148,0.81799,0.74799\}
$$
the ranking of grey relational degree is gained: $R[1]>R[2]>R[3]>R[4]>R[5]$. The key collision avoidance ship is determined, which is ship 1; moreover, the sequence of avoiding target ships is obtained. It has provided the basis for circulatory collision avoidance of key ships in multi-ship encounter, and laid a foundation for collision avoidance realization.

\section{B. Establishment of simulation interface}

In order to provide convenience for applying grey relational decision-making analysis in ship collision risk degree, and make data input convenient, fast and easy to compile, a calculation interface of collision risk degree is designed ${ }^{[10]}$. The interface includes three parts: input module: parameters of our ship and various target ships; calculation module: to determine evaluation parameters, grey relational coefficients and grey relational degree of measuring ship collision risk degree; output module: to output grey relational degree and ship collision risk degree ranking.

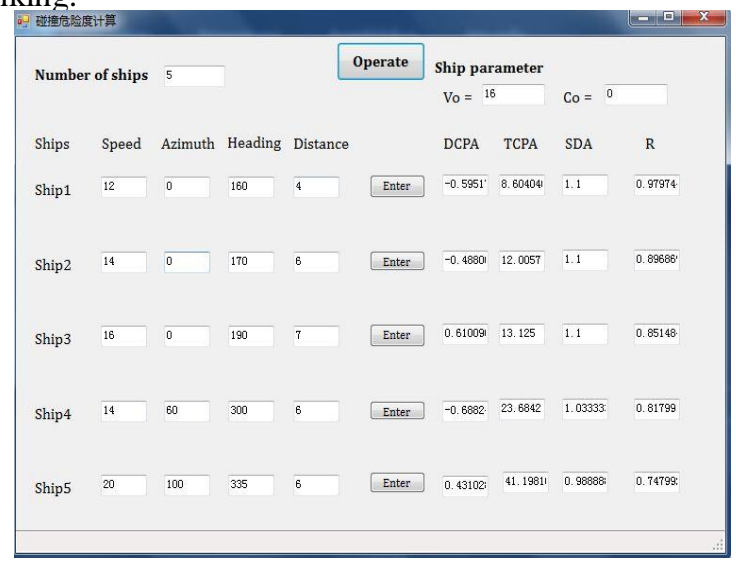

Figure 4. Output interface of ship collision risk degree ranking

\section{Analysis of simulation result}

By changing ship collision avoidance simulation parameters of risk degree via grey relational decisionmaking, the changing curve and the influence on risk degree are obtained:
(1) The sailing speed of various target ships is changed from 12 to 25 uniformly, and thus the changing curve of ship collision risk degree determined via grey relational degree is obtained, as shown in Fig. 5:

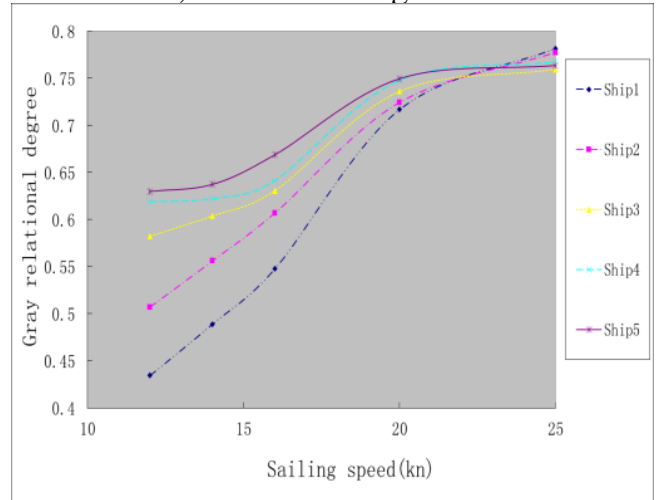

Figure 5. Variation diagram of sailing speed and grey relational degree

As shown in Fig .5, with the increase of speed, grey relational degree of the target ship in encounter rises successively. Ship 5 has the highest change rate of grey relational degree. Besides, when the speed reaches 20-24, grey relational degree of various target ships is in a steady state and reaches the maximum value. Therefore, the conclusion is that speed is a major factor of affecting judgment for risk degree in ship encounter, and it is in direct proportion to grey relational degree.

(2) During data input, other initial parameters remain unchanged and azimuth angles of the five ships are set as 0 , $60,120,180$ and 240 respectively. The encounter situation of five ships changes from end-on encounter to crossover encounter, and then transforms into overtaking encounter. The generated curve is presented in the following figure:

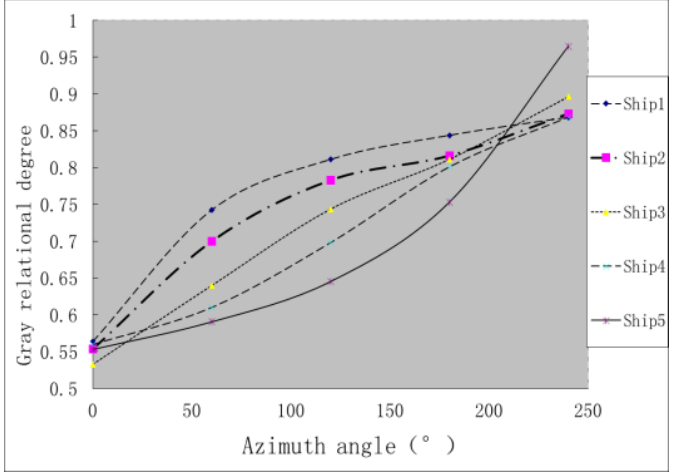

Figure 6. Changing curve chart of azimuth angle and grey relational degree

As shown in Fig.6, with gradual increase of the azimuth angle between various target ships and own ship, grey relational degree of the target ship rises slowly, but the risk degree ranking remains unchanged. Ship 1 is still the key collision avoidance ship. However, when the azimuth angle reaches $200^{\circ}$, the encounter situations between various target ships and own ship change, and ship 5 becomes the key collision avoidance ship. Moreover, change happens to the ranking. Therefore, directional change of the coming ship will affect ship collision risk degree ranking.

(3) During data setting, other initial parameters remain unchanged and relative distances between the encountering 
ships and own ship are set as 4, 6, 8, 10 and 12. The generated curve is presented in the following figure:

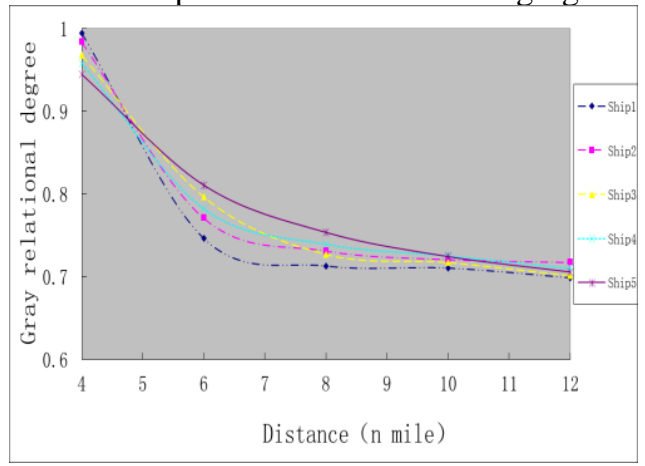

Figure 7. Variation diagram of distance and grey relational degree

As shown in Fig.7, with gradual increase of the distance with target ships, the overall collision risk degree presents a decreasing trend. When the distance reaches 10 , grey relational degree of risk degree between various target ships and own ship almost remains unchanged. Besides, the risk between own ship and various target ships is eliminated. Thus the influence of distance on ship risk degree ranking can be gained.

\section{CONCLUSIONS}

Determination for collision risk is one of the key points of automatic ship collision avoidance decision-making system. However, due to relativity and uncertainty of collision risk, uniform collision risk evaluation cannot be gained quickly and accurately during ship encounter. Based on grey relational analysis and relevant factors of affecting ship collision risk degree, this paper gains the strategy of determining key collision avoidance ship on the basis of grey relational degree. Simulation is conducted, and the interactive interface of ship risk degree ranking is established for this strategy. Moreover, the influence of relevant parameters on this strategy is analyzed, and effectiveness and feasibility of the strategy are verified. It has laid a foundation for seaman to rapidly and accurately determine the key collision avoidance ship and collision avoidance sequence under ship encounter. Thus seaman's efficiency of executing automatic collision avoidance is improved.

\section{ACKNOWLEDGMENT}

It is appreciated that this research is subsidized by funding from the Fundamental Research Funds for Central universities. (No. HEUCFX41305)

\section{REFERENCE}

[1] WangZesheng, Shichaojian.An Improved Neural Network Based Model of Collision Risk Index.Navigation of China [J]. 2007, 70(01)07-29.

[2] ZhuXiaolin, XuAnzhen. A Model based on neural net works for the risk of the Collision between ships. J.uazhong Univ.of sci. \& Tech .2000, 28(10):52-55.

[3] HuangXianxin, ShaoZheping. Risk Factor Evaluation on the Navigational Channels of Xiamen . Port Based on Fuzzy Comprehensive Evaluation. Journal of Jimmie University (Natural Science).2013, 18(3):116-119.

[4] SHINYA N, KUNIJI K.A study on the safety assessment of marine traffic.The Journal of Japan Institute of Navigation, 1994,92:101-111

[5] ChenXuejuan. Optimize Fuzzy Controller for Collision Avoidance by using BP Neural Networks. Journal of Hunan University.2003.15(4) : 68-70.

[6] Sunxiaodong,Jiaoyue,HuJinsong. Research on Decision2Making Method Based on Grey Correlation Degree and TOPSIS. Chinese Journal of Management Science [J]. 2005, 13(04)06-14.

[7] WuJie,Liuyian,Zhouxiaohua.Ship collision Avoidance Decision based on Grey System[R].Dalian: Chinese Society of Naval Architects and Marine Engineers, 2005.

[8] LiHongyan.Study on the calculation method of grey relationship degree [J].Systems Engineering and Electronics.2004, 09:12311233

[9] YangBaochen, ChenYue. Grey Relational Decision-making Model Based on Variable Weight and TOPSIS Method.Systems Engineering.2011.29 (6):106-112.

[10] ZhengZhongyi.Research on Automatic Decision-making System of Vessel Collision Avoidance [D].DaLian: Dalian Maritime University.

TABLE I. PARAMETERS OF FIVE TARGETS SHIPS AND EVALUATION

\begin{tabular}{c|c|c|c|c|r|r|r|r}
\hline $\begin{array}{c}\text { Serial } \\
\text { number }\end{array}$ & $\begin{array}{c}\text { Running } \\
\text { speed V }\end{array}$ & $\begin{array}{c}\text { Azimuth } \\
\text { angle B }\end{array}$ & $\begin{array}{c}\text { Heading } \\
\text { direction C }\end{array}$ & Distance D & DCPA & TCPA & K & SDA \\
\hline Ship 1 & 12 & 0 & 160 & 4 & -0.5952 & 8.604 & 1.333 & 1.1 \\
\hline Ship 2 & 14 & 0 & 170 & 6 & -0.4881 & 12.01 & 1.143 & 1.1 \\
\hline Ship 3 & 16 & 0 & 190 & 7 & 0.6101 & 13.13 & 1.000 & 1.1 \\
\hline Ship 4 & 14 & 60 & 300 & 6 & -0.6882 & 23.68 & 1.143 & 1.033 \\
\hline Ship 5 & 20 & 100 & 335 & 6 & 0.4310 & 41.2 & 0.800 & 0.989 \\
\hline
\end{tabular}

